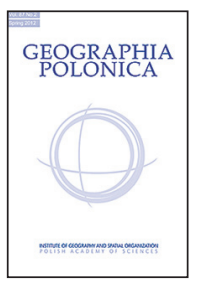

\title{
INVESTIGATING THE EMERGENCE OF SOFTWARE DEVELOPMENT CENTRES IN CENTRAL AND EASTERN EUROPE
}

\author{
GRZEGORZ MICEK \\ Institute of Geography and Spatial Management, Jagiellonian University \\ Gronostajowa 7, 30-387 Kraków, Poland \\ e-mail: g.micek@geo.uj.edu.pl
}

\begin{abstract}
The emergence of foreign software development centres (SDCs) in Central and Eastern Europe has led to some debate over the reasons and consequences of location decisions. This paper analyses those factors that influence location and also the consequences of foreign direct investment in software development centres in Bulgaria, Estonia and Poland. Foreign companies are compared and contrasted with the indigenous SDCs which are subcontractors for foreign companies or export to foreign markets. This paper questions the degree to which cost-related considerations influence location decisions, contrasting their significance with 'return migration' and the search for highly qualified graduates. To ward off growing wage pressure, SDCs provide more value-added services. Foreign SDCs move up the value chain, acquiring new competences. It may be argued that an increasing shift can be observed from a dependent mode based on a dependency on a foreign headquarters to a developmental type characterised by growing freedom. The local embededdness of foreign SDCs in the analysed countries is usually limited. However, 'backshoring' will not occur in the near future due to their high quality of work and improved efficiency.
\end{abstract}

Keywords: software development centres (SDCs), offshoring, foreign direct investment, return migration, Central and Eastern Europe (CEE).

\section{INTRODUCTION}

Central and Eastern Europe has recently become an area of interest for multinational companies (MNCs) operating in the software industry. Highly qualified staff with a solid grounding in mathematics and algorithmics seem to provide an excellent environment for the largest players to establish software development centres. The evidence presented by Gentle and Howells (1994) suggests that global competition is appearing from a number of new sources around the world, including Central and Eastern Europe. The major centres of offshore supply are India, Ireland and Israel (Trends 2004) and emerging hubs can be found in the Philippines, China and Central and Eastern Europe (in- cluding Russia). MNCs often develop a hybrid strategy whereby the activity is shared between some domestic capacity, "nearshore' capacity in CEE (for Western European MNCs) and offshore locations such as China, India and the Philippines (Dossani and Kenney 2007).

The growing interest in the emergence of foreign software development centres ${ }^{1}$ (foreign SDCs) in Central and Eastern Europe (CEE) raises the question of the reasons behind and the consequences of location decisions. This paper deals with this issue by analysing those factors that influence location and the consequences of foreign direct

1 SDCs differ from Offshore Development Centres (Arora et al. 2001), as the latter unit does not require foreign ownership. 
investment (FDI) in software development centres in $\mathrm{CEE}$; in this paper, these are represented by companies registered in Bulgaria, Estonia and Poland. Foreign companies are compared and contrasted both in terms of these reasons and consequences with the indigenous SDCs, which are subcontractors for foreign companies or which export to foreign markets. This article aims to consider the central factors behind the emergence of foreign SDCs. Consequently, the paper develops a typology of analysed companies based on their size, export level, and the role that labour costs play in determining the company's location. Secondly, this paper aims to assess the impact of FDI on the local economy. The paper presents a new model for understanding the emergence of foreign SDCs in CEE. The large role that cost-related considerations play in location decisions is questioned by contrasting their position with other factors like the search for highly qualified graduates and 'return migration'. A new insight into the position of SDCs within value chains is also presented, based on an observed shift towards a more 'developmental' mode of software FDI in CEE.

\section{THEORETICAL FRAMEWORK: DEFINITIONS AND METHODS}

For the purpose of this paper, the foreign software development centre is considered to be the subsidiary of a foreign software company, whose main activity is the development of both software solutions and the modules for them. Hence, this wide definition includes both enterprises offering final products and those providing simple code writing. SDCs undertake work of varying degrees of sophistication, but typically employ a much higher percentage of computer science graduates and software engineers than companies carrying out localisation, manufacturing and distribution of software packages $^{2}$, which have been excluded from the analysis. The minimum size of a soft-

\footnotetext{
${ }^{2}$ See discussion in Crone (2002).
}

ware development centre in CEE is considered to be a firm that employs at least five people.

Coe (1997b) has identified three main forms of footloose or non-market based FDI in the software industry: offshore data processing (meaning business process outsourcing - BPO), offshore programming ${ }^{3}$ (including SDCs) and software packaged production. SDCs may be found among five types of overseas companies operating in Ireland distinguished by Crone (2002): (1) localisation, manufacturing and distribution of software packages ${ }^{4}$; (2) software supporting subcontractors; (3) software development centres; (4) international software and computer services firms serving local markets and (5) acquired former indigenous companies. The findings of Coe (1999) and Crone (2002) show that for Ireland (1) software product manufacturing and (3) software development centres each account for approximately half of the jobs among the leading overseas software firms.

Given the aim of this paper, the analyzed software development centres that have been selected have been limited to those which relocated part or all of their activities from abroad. Indigenous SDCs operating on foreign markets have been treated as a second group: it is worth mentioning that they employ a substantial number of software developers in some countries and have made a significant contribution to the growth of the software industry. For instance, in the Polish city of $\mathrm{Krakow}^{5}$, the more than five thousand

3 The most important form of offshore programming is software code writing, followed by program and architecture planning and testing (Hietala et al. 2003).

${ }^{4}$ As with manufacturing, software may be produced to meet a particular client's demand ('customised') or as a standardised product ('packaged'). The production of packaged software generally posses higher quality and reliability requirements and entails substantially larger capital investments. Customised software development involves close interaction between the development team and the end-user.

5 Krakow, with the centres of Motorola, IBM and Google, is one of the major Polish hubs of 
employees in Polish-owned IT companies accounts for $84 \%$ of the total employment in the city's software industry (Micek 2006).

This paper does not intend to contribute to the popular issue of the number of jobs being offshored from a home country. The on-going debate over this matter has been recently summarised by the US Government Accountability Office (International Trade 2005), that has clearly stated that there are no reliable statistics measuring the scope and scale of offshoring. On the contrary, the come-back phenomenon illustrated by a few cases of foreign companies returning to the US ('backshoring') as a result of customers' complaints and the reduced efficiency of offshore work has been recently described by Malecki and Moriset (2008).

The Eurostat data on employment in the software industry shows that the number of employees in Western European countries is still increasing due to the fact that, instead of low-skilled activities, there are new competences acquired by companies (Guzik and Micek 2007). These considerations are, consequently, an indication of the durability of the expansion-based mode of FDI in Europe.

Although outsourcing and offshoring are often used interchangeably, these terms represent two different dimensions. By outsourcing, I mean that other firms take over operations that were previously conducted within the firm. It is important to note that relocation is not a prerequisite for outsourcing (Ali-Yrkkö and Jain 2005). Offshoring, in turn, is understood to mean relocating activities from one country to another, but not necessarily from one firm to another. Offshoring may be done in two ways: internally, through the establishment of foreign affiliates (sometimes called captive offshoring, involving FDI); or by outsourcing software development to a third-party service provider (offshore outsourcing). Software development centres are obviously classified within the first type. Offshoring is sometimes replaced by the term 'nearshoring' when describing a

foreign investment in the software industry. relocation which occurs within short distances, in particular within Europe (from Germany to the Czech Republic or Poland) or North America (from the US to Canada).

It is worth mentioning that besides software developed by software companies, foreign back-offices also exist which produce software for internal use. Units of non-software companies which develop software internally have been excluded from this analysis.

The results included in this paper are based on in-depth interviews in software companies and interviews with key informants conducted under the MOVE (Moving Frontier: Delocalisation of Labour Intensive Industries) project financed under the $6^{\text {th }} \mathrm{EU}$ Framework Programme. The enterprises that were studied are involved in outsourcing or subcontracting for foreign companies in five countries: Bulgaria, Estonia, Greece, Poland and the United Kingdom. Among the main issues covered by the interviews were the sources of competitive advantages of companies, location and relocation factors, operational and structural changes that occurred after relocation, and the consequences of relocation. One hundred and two interviews were conducted within the $\mathrm{PhD}$ project about the factors and mechanisms of the geographical concentration of the IT industry in Poland were also used in support of the main arguments.

On the basis of the assumptions about the size and ownership of companies, a group of 97 software development centres were chosen from a larger database of 153 software companies which were interviewed under the MOVE project in Bulgaria, Estonia and Poland. The constructed database consists of 61 indigenous softwarehouses involved in outsourcing or the subcontracting for foreign companies and 36 SDCs owned by foreign entities. These two groups were compared in terms of the main location factors and competitive advantages. Statistical analysis was conducted in order to identify significant differences between these two groups of companies. The t-test was used for independent samples (in combination with the Levene 
test on homogeneity of variation), and the post-hoc Tamhane test was used when there was a heterogeneity of variation.

This paper will firstly survey some of the debates surrounding location factors and the emergence of FDI in what were once less developed countries. It will also briefly deal with the consequences of FDI. Secondly, the impact that these location reasons have on local growth is assessed in the case of foreign SDCs which operate in CEE. Thirdly, the impact of SDCs on local economies will also be considered.

\section{LOCATION FACTORS IN THE SOFTWARE INDUSTRY - LITERATURE REVIEW}

As Arora et al. (2001, p.1270) argue, the Indian success story of attracting FDI 'has been a combination of resource endowments, a mixture of benign neglect and active encouragement from a normally intrusive government, and good timing'. There are many reasons for FDI in the software industry. A favourable tax regime was one of the main factors in the 1980s (Coe 1997a). Nowadays, the low cost of labour input and the availability of skilled staff are among the most important reasons. Other factors include: the low start-up costs; the infrastructural investments, often made by the public sector; and significant, prior investments in educational services. A large investment in human capital associated with a significant outward shift in demand for education, resulting in the entry of private educational providers, also enhances the range and scope of IT skills. Organisational changes and internal restructuring may lead to the outsourcing of IT-related non-core activities (Coe 1997a). However, the software industry is a clear example of an industry where the flow of ideas has been as important as the flow of physical capital (Commander 2004; Crone 2003). Therefore, contingent events may also be significant in attracting foreign investment.

The rise of software development centres may be explained in terms of classical location factors. Many papers support the view that the most important motive for offshoring is lower labour costs (e.g. Carmel and Agawar 2000; Girma and Görg 2002; Ali-Yrkkö and Jain 2005). However, additional costs, such as those connected to management and communication, make the cost difference clearly smaller than the wage difference. Relative to US costs, typical cost savings from offshoring fall between 20 and 40 per cent depending on the type of work (Trends 2004). For programming, the cost savings are closer to 20 per cent, while for $\mathrm{BPO}$, the current savings are in the range of 40 per cent. Savings on maintenance and support are around 25-30 per cent. Relative to Canadian costs, savings would be about 10-15 per cent lower (Huws et al. 1999). CIO Magazine (Overby 2003) estimates 'the hidden cost' of moving IT work offshore to be between 15-57 per cent of the contract's value. In reality, most IT organisations save between 15-25 per cent during the first year; by the third year, cost savings often reach 35-40 per cent as companies 'go up the learning curve' and modify operations to align themselves to an offshore model (Davison 2004).

The rise of the export-oriented software industry has drawn attention to the offshoring of more highly-skilled information processing work. The new global distribution of work in this sector follows yet another pattern. In this case, a good supply of highly skilled workers, especially IT professionals, constitutes an important attraction (Huws et al. 1999). Despite the high degree of formalisation of the knowledge involved in package software development, considerable room is left for creativity and ingenuity and for tacit knowledge based on experience. Solutions are changing so fast in the software industry that knowledge of a particular operating system, programming language or technology is not as important as the ability to learn and adapt to change. The adaptability of staff is the core factor that determines the potential success of foreign SDCs (Arora et al. 2001).

In Arora's et al. (2001) research, the authors expected that the most important reason for American companies choosing Indian vendors was the low cost. Many American respondents downplayed the issue, insisting 
that cost was a relatively minor consideration (Arora et al. 2001). The first research question therefore is: what is most significant when choosing the location for foreign SDCs or a subcontractor by a foreign company? Is it lower labour costs, access to a skilled labour force, or other factors?

The infrastructural costs in developing countries are significantly different from the costs in developed countries. For example, telecommunications and other infrastructurerelated costs are sometimes higher, while others, such as rent and taxes, are often lower.

Public policies and, in particular, incentives may also attract FDI, although it is generally agreed that their role is significant only in the final stages of a location decision. The availability of tax incentives has induced large computer corporations to establish software development centres in Taiwan and Singapore (Correa 1996). Ireland, after it joined the EU, initiated a series of progressive tariff removals and established a corporate tax on the manufacturing sector. By not taxing export profits, the Indian government created a powerful incentive for entrepreneurs to concentrate on exporting (Dossani and Kenney 2007). Although criticised by some (D'Costa 2003), it sensitised Indian business to the global market.

There are remarkable social (language difficulties) and cultural barriers to offshoring. Outsourcing decisions are hampered by a lack of trust and a perception of risk among clients who are uncertain of the skills, capabilities and credibility of potential foreign subcontractors. Potential information leakage and data security are a concern for investors (Lai et al., 2004). Lack of continuous clientdeveloper interaction is another delocalisation barrier. Despite good communications links, interaction between an employee and a customer needs to be face-to-face. All these concerns have meant that nearshoring is becoming a more attractive option as it enables face-to-face communication. A relatively close time-zone is also reported by American companies as being one of the most important advantages of CEE locations.

\section{MECHANISMS OF FDI RELOCATION - LITERATURE REVIEW}

The mechanisms (induced by various sets of factors) are also important in understanding the phenomenon of the growth of SDCs. In the initial phase, Indian engineers were moved to work sites in developed countries (Arora and Athreye 2002, D'Costa 2003, Heeks 1996, Schware 1987). Some of them returned to set up American companies in India; others became managers in the US and then made decisions about offshoring. The research carried out by Saxenian (2002) has shown that one fourth of managers in newly established firms in Silicon Valley have executive directors of Indian or Chinese ori$\operatorname{gin}^{6}$. They use their Indian operations much in the same way as Indian software export firms do, to tap into a large pool of relatively cheap but skilled workers that can provide software services for US based customers. Virtually all are headed by entrepreneurs of Indian origin and started their existence, as did many of the leading Indian companies, by supplying software professionals, such as programmers and system analysts, to clients in the US. These technically skilled 'Argonauts' (Saxenian 2006) "sail" back and forth between their home countries and their other home in Silicon Valley. This brain circulation unsurprisingly generates innovative and value added trajectories in the Argonauts' home countries and regions.

In relation to CEE, the second research question may be posed: how often are managers of CEE origin involved in offshoring decisions? In other words, the significance of 'return migration' in the emergence and growth of software companies, meaning personal returns ('ex-pats') or remotely managing a company operating in the country of origin, will be analysed.

${ }^{6}$ It must be kept in mind that these directors had been identified by their names. Some of them may have had Chinese or Indian surnames, but would have been, for instance, fifth generation Americans. 


\section{NEW TRENDS AND CONSEQUENCES OF FDI IN THE SOFTWARE INDUSTRY - LITERATURE REVIEW}

Turok (1993) provides a useful conceptualisation of the different consequences of FDI for the local economy. He distinguishes between 'developmental' and 'dependent' models of growth. In the first model, corporations are deeply embedded in the local economy through the creation of a network of sophisticated, interdependent links which support the expansion of local firms and generate self-sustaining growth for the cluster. Young et al. (1994) distinguish between two types of 'developmental' FDI. Firstly, MNCs may become locally embedded through networks of quality suppliers, or, secondly, the development FDI may be based on research and development potential. The latter type depends upon the availability of skilled labour and creative after-care policies which serve to increase $R \& D$ investment (Young et al. 1994). In contrast, the 'dependent' scenario has negative implications, being based upon weakly embedded subsidiaries that develop low-tech subcontracting agreements with local suppliers or are not embedded at all (Coe 1997b). From the classifications of Turok (1994) and Young et al. (1994), the third research question arises: are analysed foreign SDCs more 'developmental' or 'dependent' types of FDI?

The consequences of the emergence of SDCs for a host country are multidimensional. Growing labour costs may constitute a danger for offshoring. There is an increase in software specialists' wages in India, which, over the past few years, have been increasing at an annual rate of somewhere between 15-25 per cent according to one of the vendors (Ali-Yrkkö and Jain 2005). The local embeddedness of foreign software development centres in Western Europe is quite low in comparison to companies producing packaged solutions. Crone (2002) shows that there are few direct trading links between MNCs operating in Ireland and indigenous firms, and relatively few indigenous spin-offs from software MNCs. A majority of large foreign firms are part of international value chains with limited local clustering, which is shown in the case of Flanders (Larosse et al., 2001). Most of the big IT companies have to align their alliance strategies with their headquarters abroad, thus limiting the scope of local cluster development. However, a few of the biggest players (e.g. Microsoft and Symantec in Ireland) purchase a majority of their services and materials locally.

Studying the offshored operations, Arora et al (2001) have not studied the type of operations that are being undertaken, and have found any evidence that these activities were technologically very sophisticated or critical to US business. He insisted that some Indian companies had troubles when it came to moving up within the value chain. A similar conclusion has been drawn by Dossani and Kenney (2007). Therefore, the question about the scale of moving up the value chain emerges.

\section{REASONS OF THE EMERGENCE OF INDIGENOUS AND FOREIGN SDCS IN CEE}

In terms of the types of overseas companies distinguished by Crone (2002) in CEE, the network of foreign software supporting subcontractors is relatively poorly developed. There are only a few cases of acquisitions of indigenous companies by MNCs, although these processes were enhanced until 2006. The most common in terms of the number of companies are small foreign investments in firms providing software and computer services serving local markets, which are mainly sales offices. It means that the predominant process is the expansion of sales offices, with only limited capabilities in localisation and software development. However, new significant investment in software development centres has taken place in CEE during the last five years.

The conducted research has shown that the location and the competitive advantage of foreign software development centres stems from the intensity of skills gathered 
in the locality. Most of the SDCs' managers (including foreign managers) interviewed for this study commented on the excellent programming and coding skills available in the selected countries. The CEE staff of foreign SDCs have the ability to assemble 'functional' teams of engineers at very short notice. There are usually graduates from local (on average $60-70 \%$ ) universities. One American SDC has a significant share $(7 \%)$ of $\mathrm{PhDs}$ employed. Both leading foreign and indigenous software companies do not tap into the pool of graduates from private universities, because that might create potential negative signals to their customers. In this way, they hope to maintain quality (Arora et al., 2001).

In some interviews, managers of foreign SDCs in Poland commented on the gradual change of their main goals. The internal advantage of SDCs in CEE, formerly based on low costs, is now becoming more innovationbased. The labour intensity of the conducted activities is ranked fourth among the competitive advantages of the analysed companies (tab. 1). Greater significance had been placed on skill-intensive products and design, and of $R \& D$ capabilities. It is clear that the costrelated reasons of foreign investments are less important than the race for highly qualified professionals, who constitute a competitive advantage for many foreign and indigenous SDCs. However, an interesting phenomenon is the growth of a large group of American SDCs which report no profits in CEE. This group of subsidiaries is treated by parent companies as cost-oriented centres where there are no profits. Such a strategy allows them to lower the taxes paid in a host country.
Among the quantitative variables (employment, labour cost, turnover, exports), only share of the export in total sales differs between indigenous and foreign software development centres (tab. 2). The t-test for independent samples supports the thesis that there is a significant difference between the mean of export share for foreign $(38 \%)$ and local companies $(67 \%)$.

There is a substantial difference between the technologies used. These are indigenous companies which use cuttingedge technologies $(87 \%$ of the total number of local firms in contrast to only $58 \%$ of those that are foreign). The difference between the means in these two groups of companies is significant on the 0.05 level. The position within the value chain was changed in both types, but upgrading was more often observed among local companies $(75 \%$ of them). A brief outlook at the evolution of software services in Poland demonstrates that indigenous firms were very quick to migrate to newer platforms and to adapt to new technologies that are related to software development.

The strategies of foreign companies differ from those implemented by indigenous firms. Local companies, more often than foreign centres, base their strategies on innovativeness (66\% to $50 \%$ of firms and both categories). The objectives of foreign enterprises are often associated with cost-related considerations. There is no significant difference in the performance of an indigenous and a foreign company's performance. This can be clearly seen in the case of the ratio describing the turnover

Table 1. Competitive advantages of foreign and indigenous SDCs

\begin{tabular}{lcc}
\hline \multirow{2}{*}{ Sources of competitive advantage } & \multicolumn{2}{c}{ Foreign SDCs } \\
\cline { 2 - 3 } & \multicolumn{2}{c}{ Share of companies (\%) } \\
\hline Skill intensive products & 78 & 97 \\
Design / Product development & 61 & 67 \\
Research and Development & 47 & 31 \\
Labour intensive products & 42 & 34 \\
Distribution \& marketing & 22 & 28 \\
Capital intensive products & 17 & 15 \\
Other & 11 & 5 \\
\hline
\end{tabular}

Source: enterprise survey. 
Table 2. Basic characteristics of indigenous and foreign SDCs, 2004

\begin{tabular}{llrr}
\hline Indicator & Type of SDC & Mean & $\begin{array}{r}\text { Standard } \\
\text { deviation }\end{array}$ \\
\hline Total employment & Indigenous & 89.3 & 211.72 \\
\cline { 2 - 4 } $\begin{array}{l}\text { Labour costs as \% of total cost } \\
\text { (1- considerably smaller, 5-considerably higher } \\
\text { than when they started operation) }\end{array}$ & Foreign & 56.6 & 80.18 \\
\cline { 2 - 4 } Turnover (in thousand EUR) & Foreign & 3.4 & 1.43 \\
\hline \multirow{2}{*}{ Exports as \% of total sales } & Indigenous & 8318.9 & 22814.25 \\
\cline { 2 - 4 } & Foreign & 4361.9 & 12793.39 \\
\hline Turnover per 1 employee (in thousand EUR) & Indigenous & 38.4 & 31.45 \\
\cline { 2 - 4 } & Foreign & 66.5 & 33.87 \\
\cline { 2 - 4 } & Foreign & 53.4 & 62.01 \\
\hline
\end{tabular}

Note: significant statistical differences $(0.05$ level) exist for all the presented variables (t-test for independent samples in combination with the Levene test on homogeneity of variation and the post-hoc Tamhane test was used when there was a heterogeneity of variation).

Source: enterprise survey.

per one employee. No significant difference between the two types of companies can be observed.

With regard to the mechanisms of location decisions, the scale of 'return migration' in order to set-up a company has been assessed. There is a group of experienced programmers who have returned from abroad to work in Poland and Bulgaria. A majority of them return to set up their own company, sometimes to start working with foreign colleagues. Rather more interesting are the cases of those who did not come back, but instead managed to establish a foreign subsidiary in Poland and Bulgaria. These are not single cases: about one third of foreign SDCs in Krakow have been established in the city as a result of the Polish origin of their managers or the experience of studying in Poland (Micek 2006). Moreover, except for one case, 'Argonauts' who leave the US in order to set up companies in Krakow are in reality the mirror imagea reflection of twentieth century outmigration from Poland to the US.

The policy solutions devised in CEE countries only weakly focus on indirect incentives like educational or reskilling programmes. Of greater importance might be direct incentives from public government.
From 2005, companies which conduct business processing outsourcing may obtain an exemption from corporate tax in Polish Special Economic Zones. However, only a few software companies have chosen to make use of these exemptions.

\section{CONSEQUENCES OF THE EMERGENCE OF INDIGENOUS AND FOREIGN SDCS IN CEE}

It may be argued that the consequences of foreign investments in software development centres are mainly localised. From the negative perspective, an exodus of software developers from small and medium indigenous enterprises is taking place in CEE. The issue commonly raised by key informants is the wage-pressure on local companies. They need to raise wages in order to retain employees.

The positive impact of foreign SDCs on the local economy can be clearly seen: the new well-paid, highly skilled, white-collar class is growing. $60 \%$ of companies insist they pay salaries above the industry average. Based on the t-test for independent samples, no differences are reported for salary levels 
Table 3. Main indicators of the software industry for selected European countries, 2004

\begin{tabular}{lrrrrr}
\hline Variable & EU-25 & \multicolumn{1}{c}{ UK } & Germany & Poland & Bulgaria \\
\hline Value added (in million EUR) & 152337 & 47006 & 28375 & $1140^{*}$ & 77 \\
Turnover (in million EUR) & 308209 & 80365 & 56840 & $3281^{*}$ & 204 \\
Persons employed & 2483170 & 573424 & 370346 & $71280^{*}$ & 12183 \\
Average personnel costs (in thousand EUR) & 49.0 & 55.9 & 57.7 & $16.0^{*}$ & 4.6 \\
Value added per person employed & 61.3 & 82.0 & 76.6 & $16.0^{*}$ & 6.3 \\
(in thousand EUR) & 123 & 146 & 133 & $180^{*}$ & 137 \\
Wage adjusted labour productivity in \% & & & & & \\
\hline
\end{tabular}

*- data for 2003

Source: Eurostat in: Guzik, Micek (2007), modified.

between local and foreign-owned companies. However, only $48 \%$ of indigenous SDCs report higher salaries in contrast to $63 \%$ of foreign SDCs. Average salaries in three CEE countries vary significantly, with the highest observed in Estonia and Poland, whereas in Bulgaria they are 4-5 times lower (tab. 3). It may be argued that the wage difference between Western Europe and some CEE countries (e.g. Poland) will in all probability be rectified in the next five to eight years.

Foreign companies appreciate the plentiful and growing supply of third level computer science graduates, although few of them have been acquired from neighbouring countries (as with the case of experienced Ukrainian managers working for Polish companies). What was pointed out by key informants is that MNCs helped develop labour skills for the indigenous industry, but on the other hand, competition for skilled labour has also emerged: a similar problem was observed in Ireland (Crone 2002). According to key informants, indigenous companies have to deal with the problem that there is a shortage of experienced managers and project leaders. The t-test shows that there are no significant differences between the level of labour scarcity experienced by foreign and indigenous SDCs.

With regard to labour mobility, in many CEE countries it is very difficult to retain experienced project managers with 4-6 years of experience. In Poland, the turnover rates varied in 2004 from below $1 \%$ in the most distinguished foreign SDC, up to $10-15 \%$ in some indigenous softwarehouses. As in the case of
India, some employees in foreign companies are lost to firms that are located abroad: this is the case in Bulgaria and, to some extent, Estonia. On the other hand, two years after a German programme was established to open up the labour market for foreign software developers, less than five hundred Polish programmers had emigrated. The small scale of outmigration was due to the rapid growth of salaries in the Polish software market and the growing demand for skilled software developers and testers.

To answer the second research question, the scale of the linkages of new entrants must be assessed. However, a majority of foreign companies do not have local subcontractors: only $19 \%$ of firms cooperate at the local level. Consequently, some foreign software development firms do little to stimulate indigenous growth. A majority of large foreign firms are part of international value chains with limited local clustering. Most large IT companies have to align their alliance strategies with their headquarters which is located abroad, thus limiting the scope for local development. Surprisingly, a relatively small number of indigenous companies cooperate with local subcontractors $(21 \%$ of foreign entities). A clear feature of the operations of companies in the software industry is, therefore, a low level of local embeddedness. The local networks of foreign SDCs in CEE (especially those operating outside capital cities) in the analysed countries are usually limited to catering, security and translation services. For instance, regarding multiplier effects, employment in local subcontracting 
companies cooperating with software firms constitutes only $15 \%$ of the total workforce of software companies (Micek 2008). The weak indirect and induced employment effects in Kraków's local milieu due to the functioning of service centres has been studied by Micek et al. (2010), who conclude that they may generate about 270 new jobs in supplying companies per 1,000 job-places in service centres.

Similar conclusions have been drawn by Crone (2002) and Larosse et al. (2001), who report the low-level of local embeddedness of foreign software companies in Ireland and Flanders. Despite the weak local background, foreign SDCs in CEE are not prone to 'backshore' due to the relatively high quality of work conducted there. This became especially evident when interviewing British companies that have SDCs in CEE. They all emphasised the high quality of work and the improved efficiency of their companies operating in CEE.

\section{THE TYPOLOGY OF FOREIGN SOFTWARE DEVELOPMENT CENTRES IN CEE}

Software development centres vary in terms of employment and the role that cost plays in location decisions and the operation of their companies. Not surprisingly, companies are also different when it comes to increasing exports. A two-step cluster analysis was conducted in order to make use of both qualitative and quantitative variables. There are at least three distinctive types of software companies in terms of size, export level and the role that labour costs play in location decisions and the operation of companies.

The research of Dossani and Kenney (2007) suggests that the commonly held assumption that only larger firms go offshore is false. The conducted research shows that small and medium foreign SDCs expand their operations, too. The majority of foreign SDCs in the sample employ less than 30 people. Until recently, the presence of small, niche foreign SDCs has been underestimat- ed. As in Ireland (Crone 2002), Polish and Estonian companies focus especially on developing software products for niche markets rather than providing customised services. It seems that, as in the UK (Coe 1997a,b), different subsidiaries of foreign software companies are more likely to undertake a specific function within the company rather than just providing a total range of services to the home country.

The first type (representing $23 \%$ of the total) of foreign companies consists of smaller companies (with an average of 14 employees) that base their competitive advantage on lower wages. Such cost-oriented centres have been established due to the lower cost of software development in CEE. They are largely involved in export activities: on average $71 \%$ of their turnover comes from sales. These companies operate in Bulgaria and Poland. They are highly dependant on a parent company and have not established a network of local subcontractors.

The second group of firms are represented by medium companies which are largely involved in exports (all companies report over $50 \%$ of turnover from exports): most of them sell exclusively to a foreign parent company. These enterprises have medium and lower wages in comparison to the rest of the industry and operate in the three analysed countries.

The largest in terms of share (almost 50\% of the total) is a group of enterprises of different sizes which have developed specialised solutions and have seized the opportunity to make use of highly skilled labour. They have not come to CEE because of lower labour costs. This third type of centre is opened by global players which offer salaries that are above the region's average. Their position in the value chain is significantly being improved: they gradually undertake more sophisticated tasks. After some years of operation, several centres have opened system design, marketing and sophisticated sales departments. These processes may be illustrated by the following quotation: 'Within a Polish subsidiary, there is an unwritten strategy which a Polish team implements in 
Table 4. Typology of foreign software development centres

\begin{tabular}{|c|c|c|c|c|c|}
\hline \multirow[b]{2}{*}{ Type } & \multirow{2}{*}{$\begin{array}{l}\text { Share of } \\
\text { companies }\end{array}$} & $\begin{array}{c}\text { Total } \\
\text { employment }\end{array}$ & $\begin{array}{c}\text { Exports as \% of total } \\
\text { sales in } 2004\end{array}$ & \multirow{2}{*}{$\begin{array}{c}\text { Company's wages in } \\
\text { comparison to } \\
\text { the industry }\end{array}$} & \multirow{2}{*}{$\begin{array}{l}\text { Role of low cost } \\
\text { in getting orders }\end{array}$} \\
\hline & & & Mean & & \\
\hline 1 & $23 \%$ & 13.9 & 71.0 & Average/above average & High \\
\hline 2 & $30 \%$ & 58.7 & 79.3 & Average & Low \\
\hline 3 & $47 \%$ & 74.9 & 49.5 & Above average & Low \\
\hline Total & $100 \%$ & 55.8 & 63.5 & Above average/average & Relatively low \\
\hline
\end{tabular}

Source: enterprise survey.

order to be more and more self-reliant; they employ not only software specialists but also business analysts in order to be wholly responsible for projects. They are seen by the $H Q$ as not only of very good technical quality, but also as being wholly capable of innovation. They will become better and better' (medium-sized American SDC in Poland). Therefore, it may be argued that a shift from a dependent mode based on a dependency on a foreign headquarters to a developmental type characterised by growing freedom is currently taking place.

\section{DISCUSSION AND CONCLUSION}

With regard to labour cost, there is still a gap between Poland and more developed countries. One may state there is the some exaggeration in managers' opinions. However, the vast majority of interviewed managers claimed that cost-related reasons for foreign investment are slightly less important than the race for highly qualified professionals. The largest group of SDCs develop specialised solutions and seize the opportunity to make use of highly skilled labour. They have not come to CEE mainly because of lower labour cost. Not only was there an abundance of skilled graduates that attracted FDI to CEE, but there was the 'return migration' which also influenced location decisions in some cases. About one third of foreign SDCs in Krakow have established themselves there due to the Polish origin of managers or the experience of studying in Poland. With regard to the emergence of foreign SDCs, the local embeddedness of foreign SDCs in the analysed countries is usually limited, which supports Crone's and Larosse's et al. (2001) results. However, 'backshoring' will not occur in the near future due to the high quality of work (expressed explicitly by managers of British companies in CEE) and improved efficiency.

To ward off growing wage pressure, companies provide more value-added services. Foreign SDCs move up the value chain, acquiring new competences, such as project management and some sophisticated sales capabilities for the CEE region. It seems that indigenous companies did not perform worse than foreign SDCs. Surprisingly, a much higher percentage of local SDCs reported the use of cutting edge technologies, experienced upgrading and based their strategy on innovativeness. On the other hand, the position of a majority of foreign SDCs in the value chain has been significantly being improved as they are gradually undertaking more sophisticated tasks. Having operated for several years, a number of centres have opened system design, marketing and sophisticated sales departments. Therefore, it may be argued that an increasing shift from a dependent mode based on a strong association with a foreign headquarters to a developmental type that is characterised by growing freedom is currently taking place.

\section{ACKNOWLEDGEMENTS}

I am extremely grateful to numerous managers in software companies who have generously given their time and expertise. To preserve their confidentiality, firms and respondents have not been identified. I have benefited from the support and advice by Boleslaw Domanski from the Institute of Ge- 
ography and Spatial Management (Jagiellonian University, Krakow), who has provided suggestions for this paper.

Dr Grzegorz Micek is a Scholar of the Foundation for Polish Science (program Start, 2009 edition).

\section{REFERENCES}

Ali-Yrkkö, J., and Jain, M. (2005), Offshoring Software Development - Case of Indian Firms in Finland. Keskusteluaiheita - Discussion papers, Helsinki, The Research Institute of the Finnish Economy, 971.

Arora, A., Arunchalam, V.S., Asundi, J. and Fernandes, R. (2001), The Indian Software Services Industry, Research Policy, 30, 1267-1287.

Arora, A. and Athreye, S. (2002), The Software Industry and India's Economic Development, Information Economics and Policy 14(2): 253-273.

Carmel, E., and Agawar, R. (2000), Offshore Sourcing of Information Technology Work by America's Largest Firms. Technical Report, Washington D.C: Kogod School, American University.

Coe, N.M. (1997a), Internalisation, Diversification and Spatial Restructuring in Transnational Computer Service Firms: Case Studies from the UK Market. Geoforum, 28, 253-270.

Coe, N.M. (1997b), US Transnationals and the Irish Software Industry: Assessing the Nature, Quality and Stability of a New Wave of Foreign Direct Investment. European Urban and Regional Studies, 4: 211-230.

Coe, N.M. (1999), Emulating the Celtic Tiger? A Comparison of the Software Industries of Singapore and Ireland, $\mathrm{Si}$ nagpore Journal of Tropical Geography, 20(1): 36-65.

Commander, S. (2004), Brains: What Can They do for Development?, Lecture at the London Business School and EBRD, London, 4 March 2004, Sussex Development Lecture.
Correa, C.M., (1996), Strategies for Software Exports from Developing Countries, World Development, 24(1): 171-182.

Crone, M. (2002), The Irish Indigenous Software Industry: Explaining the Development of a Knowledge-Intensive Industry Cluster in a Less Favoured Region, paper presented at $42^{\text {nd }}$ European RSA Conference, 27-31 Aug.2002, Dortmund, available from <http://www.ersa.org $>$, accessed 18 Jan. 2006.

Crone, M. (2003), Clustering and Cluster Development in Knowledge-Intensive Industries: A 'Knowledge and Learning' Perspective on New Firm Formation and Firm-Building/Firm Growth in Ireland's Indigenous Software Industry, St Andrews, 20-22 Aug. 2003, Regional Science Association International: British and Irish Section, 33rd Annual Conference.

Davison, D. (2004), Top 10 Risks of Offshore Outsourcing, Meta Group, available from <http://techupdate.zdnet.com/ techupdate/stories/main/>.

D'Costa, A.P. (2003), Uneven and Combined Development: Understanding India's Software Exports, World Development, 31(1): 211-226.

Dossani R. and Kenney M. (2007), The Next Wave of Globalisation: Relocating Services Provision to India, World Development, 35(5): 772-791.

Gentle, C. and Howells, J. (1994), The Computer Services Industry: Restructuring for a Single Market, Tijdschrift voor Economische en Sociale Geographie, 85(4): 311-321.

Girma, S., and Görg, H. (2002), Outsourcing, Foreign Ownership and Productivity: Evidence from UK Establishment Level Data. The University of Nottingham, Research Papers, 16.

Guzik, R., Micek, G. (2008), Impact of Delocalisation on the European Software Industry, in Labrianidis L. (ed.), The Moving Frontier: The Changing Geography of Production in Labour Intensive Industries, Ashgate, 229-254.

Heeks, R., (1996), India's Software Indus- 
try: State Policy, Liberalisation and Industrial Development, New Delhi, Sage Publications.

Hietala, J., Jokinen, J.-P., Bauer, L., Maula, M., Leino, V., Kontio, J. and Autio, E. (2003), Finnish Software Product, Economic Trends, 5.

Huws, U., Jagger, N., and O'Regan, S. (1999), Teleworking and Globalisation, IES Report, 358.

Lai, E., Riezman, R., and Wang, P. (2004), 9-11 Sep 2004, Outsourcing of Innovation. Nottingham, ETSG 2004 seminar.

Larosse, J., Slaets, P., Wauters, J., Bruninx, S., Simkens, P. and Wintjes, J. (2001), ICT Clusters Organisation in Flanders: Co-operation in Innovation in the New Networked Economy, in Innovative Clusters. Drivers of National Innovation Systems, Paris, OECD, 112-131.

Malecki, E.J. and Moriset B. (2008), The Digital Economy. Business Organization, Production Processes and Regional Developments, London- New York, Routledge.

Micek, G. (2006), Czynniki i mechanizmy koncentracji przestrzennej firm informatycznych $w$ Polsce [Factors and mechanisms of geographical concentration of IT industry in Poland], Unpublished Ph.D. thesis, Krakow, Institute of Geography and Spatial Management, Jagiellonian University.

Micek, G. (2008), Exploring the Role of Sticky Places in Attracting the Software Industry to Poland, Geographia Polonica, 81(2): 42-60.
Micek, G., Działek J. and Górecki J. (2010), Centra usług i ich relacje $\mathrm{z}$ otoczeniem lokalnym [Service centres and their relations with local environment], Kraków, Wydawnictwo UJ.

Overby, S. (2003), The Hidden Costs of Offshore Outsourcing, 1 Sept.2003, CIO Magazine.

Saxenian, A.L. (2002), Silicon Valley's New Immigrant High-Growth Entrepreneurs, Economic Development Quarterly, 16(1): 20-31.

Saxenian, A.L (2006), The New Argonauts: Regional Advantage in a Global Economy, Cambridge, MA, Harvard University Press.

Schware, R., (1987), Software Industry Development in the Third World, World Development, 15: 1249-1267.

Turok, I., (1994), Inward Investments and Local Linkages: How Deeply Embedded is 'Silicon Glen'? Regional Studies, 27(5): 401-418.

Trends in the offshoring of IT jobs (2004), Ottawa: Prism Economics and Analysis, Software Human Resource Council.

International Trade: US and India data on offshoring show significant difference (2005), US Government Accountability Office, October, report, \#GAO-06-116.

Young, S., Hood, N. and Dunlop, S. (1988), Global Strategies, Multinational Subsidiary Roles and Economic Impact in Scotland, Regional Studies, 22(6): 487-497.

Young, S., Hood, N. and Dunlop, S. (1994), Multinational Enterprises and Regional Economic Development; Regional Studies, 28(7): 657-678. 
http://rcin.org.pl 